\title{
APÓS O ANOITECER E KAFKA À BEIRA-MAR, DE HARUKI MURAKAMI: RELAÇÕES COM O MÍTICO E O MARAVILHOSO
}

Márcia Hitomi Namekatal

Resumo: O presente artigo propõe-se a uma análise de duas obras de Haruki Murakami, Após o Anoitecer e Kafka à Beira-Mar, sob o prisma dos mitos, contos maravilhosos e dos mukashi banashi, considerando-se as referências constantes do autor a elementos fantásticos e maravilhosos em suas obras.

Palavras-chave: contos maravilhosos; mukashi banashi; sobrenatural; inconsciente

Abstract: This article intends to analyze two works of Haruki Murakami, After Dark and Kafka on the Shore, by the viewpoint of myths, fairy tales and mukashi banashi, considering the references constantly made by the author to the fantastic and marvelous elements in his work. Keywords: fairy tales; mukashi banashi; supernatural; unconscious

\section{Introdução}

Haruki Murakami pode ser considerado o mais aclamado autor da literatura japonesa pós-moderna. Com uma obra vasta - 13 romances, ensaios, traduções e uma

1. Professora doutora na área de Japonês (Literatura Japonesa) no Departamento de Letras Estrangeiras Modernas (DELEM) da Universidade Federal do Paraná (UFPR), Curitiba, Paraná, Brasil; marcianamekata@gmail.com 
significativa quantidade de contos -, boa parte dela traduzida para vários idiomas, Murakami foi também agraciado com diversos prêmios literários. Com um estilo que já cativou leitores em diversas partes do mundo, de uma influência ocidental marcante que o situa em uma posição à parte entre os autores japoneses, enfoca em suas obras, por outro lado, elementos que vão desde a literatura japonesa clássica até a solidão e a alienação do homem japonês moderno.

Em meio ao fluxo ocidente-oriente, são perceptíveis as constantes referências a contos de fadas ocidentais e elementos míticos em diversas obras do autor. Assim, optou-se por analisar, no presente trabalho, apenas dois de seus romances: Kafka à Beira-Mar (Umibe no Kafuka, 2002) e Após o Anoitecer (Afutā Dāku, 2004), devido ao fato de que a associação de seus enredos a contos maravilhosos ocidentais conhecidos do público é mais direta, o que permite delinear melhor a análise à luz de teorias sobre mito e conto maravilhoso

Os capítulos de Kakfa à Beira-Mar alternam-se entre dois protagonistas: Kafka Tamura, um jovem de quinze anos que sai de casa em busca da mãe que o abandonara quando ele tinha quatro anos de idade, e da irmã, que a mãe levara junto; e Satoru Nakata, um homem de cerca de sessenta anos de idade, portador de atraso mental devido a um acidente inexplicável que sofrera na infância. A trama se desenrola de modo que, ao longo dos capítulos, os destinos de ambos se encontrem para que os mistérios que cercavam suas vidas se desvendem.

Após o Anoitecer apresenta um enredo que acontece em uma madrugada. É centrado em Mari Asai, que passa a noite fora de casa como forma de fugir de uma relação não resolvida com a irmã mais velha, Eri, que sofria de um distúrbio que a mantinha dormindo praticamente o dia inteiro, durante um longo período de tempo. As pessoas com as quais Mari encontra na madrugada - a maioria pertecente ao submundo de Tokyo - acabam auxiliando-a na resolução de seus conflitos interiores.

O ponto de partida para esta análise foram referências familiares ao universo dos contos maravilhosos e mitos presentes nas duas histórias: a ideia de rito de passagem de um adolescente de quinze anos em Kafka à Beira-Mar, que culmina em sua entrada na floresta como representação da busca pela resposta às dúvidas que o atormentavam - como um "mergulho" no inconsciente; e o distúrbio que sofre Eri Asai, de Após o Anoitecer, que poderia nos remeter ao conto A Bela Adormecida, dos Irmãos Grimm.

\section{Mito, conto maravilhoso, mukashi banashi: considerações teóricas}

Podemos estabelecer uma relação entre as obras de Murakami e os mitos e contos maravilhosos - formas literárias transmitidas oralmente ao longo das gerações -, através das palavras do próprio autor, proferidas em uma entrevista ${ }^{2}$ : "Quando

2. Todas as traduções de citações de críticos que surgem ao longo do texto foram feitas pela autora do artigo. 
escrevo, não faço distinção entre o natural e o sobrenatural. Tudo parece real. Este é o meu mundo"3. Strecher (1998:366) diz ainda que a intrusão usual do paranormal e de realidades alternativas são uma "marca registrada" de Murakami; de fato, uma das características marcantes em várias de suas obras é a presença de "dois mundos": o mundo real e um mundo paralelo. De acordo com o romancista norte-americano Richard Powers ${ }^{4}$, Murakami faz com que seus leitores imaginem quais as ligações que deveriam existir entre os dois mundos (de realismo banal e de fantasmagoria estranha), provocando um sentimento de estranheza em um sentido, digamos, "universal": "Murakami writes stories that make people feel strange, and strange feelings must be the hardest to put into foreign words" . No entanto, dado o seu sucesso - suas obras já foram traduzidas para mais de 50 idiomas -, parece conseguir o seu intento.

Considerando-se que estamos tratando de um autor japonês que se refere a temas míticos e maravilhosos em sua obra, tal proposição pode também ser pensada sob o viés dos mukashi banashi ("contos antigos") japoneses. Em meus estudos desenvolvidos durante o Mestrado e o Doutorado acerca do tema, pude concluir que, em termos estruturais, os mukashi banashi diferem, em muito, dos contos maravilhosos e de fadas do Ocidente, estando muito mais próximos da categoria do mito. No entanto, se pensarmos que todas essas formas literárias têm uma origem que se perde no tempo, podemos considerar que

A frase "Mukashi, mukashi..." ("Antigamente", "Há muito tempo"), proferida pelos narradores no momento em que abriam uma narrativa, além de indicar um tempo histórico passado, poderia também ser um indicativo da existência de um mundo das almas. Em tempos antigos - quando os mukashi banashi desenvolveram-se em abundância - considerava-se que a alma estava situada em um plano superior à existência (o "consciente"), ou seja, que o inconsciente localizava-se acima do limiar da consciência. As imagens que surgem nos mukashi banashi, assim, são a do homem enquanto representação do microcosmo (formado pelo consciente e pelo inconsciente), e a da espiral: homem, natureza, morte e nascimento como elementos interligados. Considerando-se o consciente a parte pertencente a este mundo e o inconsciente a parte pertencente ao outro mundo, os sonhos e os mukashi banashi existem no universo configurado pelo entrelaçamento destes dois mundos; caracterizam, assim, uma metamorfose universal que se movimenta em espiral e que faz com que a morte e o nascimento se desenvolvam.

(NAMEKATA, 2011:103)

3. "When I am writing," Murakami says, "I do not distinguish between the natural and supernatural. Everything seems real. That is my world, you could say." (PHELAN, 2005)

4. In: TANDOM, Shaun. The loneliness of Haruki Murakami. iAfrica, March 27, 2006. Retrieved 2008-04-24. Disponível em http://entertainment.iafrica.com/features/990664.htm

5. "Murakami escreve histórias que fazem com que as pessoas sintam-se estranhas, e sentimentos estranhos são os mais difíceis de serem transpostos para uma língua estrangeira." (PHELAN, 2005). 
Verificamos tais conceitos também em um contexto universal, na medida em que, segundo Eleazar M. Meletínski (1987:191), “o homem 'primitivo' ainda não separava nitidamente a si mesmo do mundo natural circundante e transferia para os objetos naturais as suas próprias características". Relacionando-se o conto maravilhoso a essa questão, Vladimir Propp (1974:70) considera que todo o desenvolvimento do conto maravilhoso e, em especial, o início, já mostra uma conexão entre o mundo dos vivos e o mundo dos mortos, através da imagem da entrada do heroi em um outro mundo - por exemplo, a floresta, ou algum reino limitado por um rio.

De acordo com Strecher (2014:15), o mecanismo pelo qual o mágico é apresentado na ficção de Murakami é chamado de "outro mundo" ou, às vezes, "o lado de lá" ("over there"). De uma perspectiva psicológica, trata-se de uma representação do inconsciente. Isso já caracteriza uma convergência entre suas obras e o universo dos mitos e dos contos maravilhosos: na já referida entrevista, ele diz que constrói túneis, bibliotecas, labirintos, corredores escuros e poços profundos em suas histórias, através dos quais seus narradores passam dos males urbanos do mundo a um imensurável abismo cósmico. Suas histórias (re)traçam uma trilha de volta ao local onde Murakami as encontrou: os psiquiatras chamariam-no de "inconsciente", ele o chama de "basement" - um local escuro, frio e quieto, um "porão da alma". Ele diz que tal local pode ser perigoso para a mente humana, e é de lá que ele tira suas histórias e as traz para a superfície, para o mundo real.

Do ponto de vista estrutural, quando se pensa na análise da estrutura do conto de magia, a primeira referência que nos vem à mente é $A$ Morfologia do Conto Maravilhoso, do supracitado Vladimir Propp que, depois de exaustivos estudos acerca da estrutura de contos das mais variadas culturas, concluiu que a grande maioria deles, partindo de uma situação inicial (que normalmente se configura em uma carência), apresenta uma sequência de 31 funções, que vão do afastamento (que pode se configurar através do afastamento do lar ou da morte de alguém próximo ao heroi), passando pelo encontro com o antagonista e as várias peripécias que levarão o heroi ao seu objetivo, que pode ser a obtenção de um bem e/ou o casamento com a princesa. Propp ponderava que nem todos os contos maravilhosos apresentavam todas essas funções; por outro lado, ainda que isso ocorresse, não poderia haver modificações significativas na ordem da sequência da narrativa.

Em função de possuírem uma estrutura bastante diversa do conto ocidental, os estudos desenvolvidos por Meletínski, discípulo de Propp, pareceram-me mais pertinentes para uma análise dos mukashi banashi japoneses. Utilizando-se de métodos semióticos estruturais através da combinação da tipologia histórica com a estrutural (ao invés da preferência pela análise sincrônica à diacrônica, característica do estruturalismo), o centro dos interesses das investigações do autor recaía sobre o mito. Meletínski partiu da ideia de que um enredo pode tanto começar com uma aquisição quanto com uma perda, e que os episódios constitutivos do conto são independentes, não havendo uma hierarquia entre os mesmos. Para ele, na antiga narrativa folclórica ainda 
havia traços de mito, predominando assim uma tendência ao sincretismo; utilizando-se de terminologias como "mito-conto maravilhoso arcaico" e "mito-conto sincrético", ressalta que encontram-se em primeiro plano a aquisição de objetos míticos (cósmicos) ou a conquista dos espíritos-guardiães. Não se obedece à típica estrutura "carência/ remoção do dano/obtenção de valores" que culminam no final feliz (casamento/ obtenção do reino) do conto de magia. Daí o fato de a maioria dos mukashi banashi não apresentar o típico "final feliz" característico dos contos maravilhosos ocidentais e, às vezes, possuir um final vago - o que repercute nas obras (não apenas literárias) japonesas, enfatizando um traço de âmbito cultural dessa sociedade.

Além do inventário de funções, Propp estabeleceu sete esferas de ação para as personagens que figuram no conto maravilhoso, cada qual compreendendo um determinado número dentre as 31 funções da narrativa. Tais esferas são as do antagonista (malfeitor), do doador (provedor), do auxiliar (ajudante), da princesa (personagem procurada), do mandante, do heroi e do falso heroi. Essas personagens, dependendo das circunstâncias, podem tomar o lugar de outra, ou seja, assumir outro papel dentro de uma mesma narrativa.

As duas obras de Murakami a serem discutidas começam, de fato, pelo afastamento do heroi de seu local de origem, com o intuito de suprir uma carência: Kafka Tamura e Nakata, de Kafka à Beira-Mar, saem de casa para convergirem seus destinos em Takamatsu, onde devem solucionar os mistérios que regem suas vidas. Mari Asai, de Após o Anoitecer, passa uma madrugada fora de casa como meio de fuga de um problema familiar, configurado entre ela e sua irmã mais velha.

\section{Após o Anoitecer}

A trama acontece em uma madrugada, e o tempo cronológico da narrativa é marcado pelo relógio que aparece no início de cada capítulo.

A protagonista da obra é Mari Asai, que decide passar a noite fora de casa. A partir de seu encontro com Tetsuya Takahashi em um restaurante na madrugada, começam a se delinear suas angústias, decorrentes de uma relação conflituosa com Eri, sua irmã mais velha. Ao contrário desta, bela e "escrava da moda" - "uma beldade", nas palavras de Takahashi (MURAKAMI, 2009:17), - Mari é introspectiva e intelectual, nutrindo um sentimento de inferioridade em relação à irmã. No entanto, na última conversa entre Mari e Takahashi, ela the relata, em tom confessional, um fato que acontecera às duas na infância, quando ficaram presas em um elevador, e do medo que sentiram; Eri abraçou Mari, numa atitude protetora. E ela diz que fora a última vez em que estiveram tão próximas, a ponto de estarem unidas “(...) num só coração, sem nada que pudesse nos separar. Depois disso, fomos nos distanciando cada vez mais. Separadas, cada uma passou a viver em seu próprio mundo.(...)" (MURAKAMI, 2009:194).

Considerando-se, assim, que existe uma rivalidade entre ambas, podemos relacionála aos contos sobre dois irmãos, conhecidos em diversos folclores ao redor do mundo: 
“Em versões mais modernas, tais como o conto dos Irmãos Grimm, 'Os dois irmãos', eles são de início indiferenciados.(...) A floresta, onde eles foram para decidir que desejavam ter uma vida própria, simboliza o lugar onde a escuridão interior é confrontada e elaborada; onde a incerteza sobre quem somos é solucionada; e onde começamos a entender o que queremos ser. Em muitas estórias de dois irmãos, um deles (...) lança-se ao mundo e corre perigo, enquanto o outro (...) simplesmente permanece em casa.(...)" (BETTELHEIM, 1992:118)

Se pensarmos em Após o Anoitecer como um "conto de fadas moderno", podemos relacionar a mencionada escuridão interior (a floresta) ao ambiente noturno por onde transitam as personagens de Murakami: é na noite que Mari expõe sua insegurança e, de forma talvez inconsciente, busca uma solução para seus conflitos. Tetsuya Takahashi, apesar de amigável, também está à procura de um sentido para sua vida: filho único, em dúvida com relação ao futuro, é contrabaixista de uma banda que ensaia durante à noite e tem uma relação conturbada com o pai, que se encontra preso. Os capítulos da obra alternam-se entre os acontecimentos que ocorrem a Mari na madrugada e o quarto de Eri. As personagens que Mari conhece durante a noite - Takahashi; Kaoru, a gerente do motel Alphaville; Komugui e Koorogui, funcionárias do motel; e Guo Dongli, a prostituta chinesa agredida por um cliente - ajudam-na, através de seus problemas pessoais, a repensar a relação com a irmã. A noite é o ambiente onde as personagens buscam um sentido para a vida, o que configura, em um âmbito mais amplo, a busca de autoconhecimento do eu contemporâneo. Cada personagem de Após o Anoitecer busca respostas, a seu modo, à vida turbulenta que levam.

Quanto a Eri Asai, esta passa praticamente todo o enredo imersa em um sono profundo, que já durava dois meses. Segundo Mari, ela acordava de vez em quando, comendo a comida que lhe deixavam, fazendo o mínimo necessário para manter-se viva; mas parecia até estar morta, visto que durante o sono não ressonava nem se mexia.

Sob o ponto de vista dos contos maravilhosos, é inevitável relacionar a condição de Eri ao conto A Bela Adormecida, dos Irmãos Grimm. Inclusive, tal referência existe no romance:

- É uma conversa um pouco estranha... Mas, dormindo, minha irmã é realmente muito bela. Muito mais bonita do que quando está acordada. Até parece que fica transparente. Eu, que sou sua irmã, chego a ficar assustada em ver tamanha beleza.

- É como a Bela Adormecida?

- É.

- E ela irá despertar com um beijo? - completa Koorogui.

- Se tudo der certo - comenta Mari. (MURAKAMI, 2009:168)

Há, ainda, outra referência a este gênero, que se repete algumas vezes ao longo da trama: 
"Que eu saiba, não - responde Mari. - Nunca fiquei doente... É por isso que lá em casa minha irmã é a delicada Branca de Neve e eu sou a robusta pastora de ovelhas.” (MURAKAMI, 2009:122)

Da mesma forma que a Bela Adormecida, Branca de Neve também cai em sono profundo após comer a maçã envenenada oferecida pela bruxa. Em linhas gerais, tanto A Bela Adormecida como Branca de Neve trabalham o tema do sono profundo como uma etapa de preparo para a conquista da maturidade. A respeito de $A$ Bela Adormecida,

\begin{abstract}
“(...) Uma reação natural à ameaça de se ter de crescer é refugiar-se da vida e do mundo que impõem estas dificuldades. A fuga narcisista é uma reação tentadora para as tensões da adolescência mas, adverte a estória, conduz a uma existência perigosa, semelhante à morte, se a abraçamos como um escape para as incertezas da vida. O mundo inteiro fica morto para a pessoa: eis o significado simbólico e admonitório do sono mortífero em que caem tudo e todos que circundam Bela Adormecida.(...) (BETTELHEIM, 1992:274)
\end{abstract}

A certa altura, é feita referência a uma imagem no quarto de Eri que, a princípio, seria um aparelho de TV mas, aos poucos, sugere-se que seja uma janela. Dentro dela, há um homem sentado, coberto por uma camada de pó e com o rosto escondido por uma máscara: é chamado de "o homem sem rosto" que, a despeito de passar o tempo todo imóvel, observa ininterruptamente o sono de Eri. Há, ainda, outra personagem que se destaca na obra: Shirakawa, funcionário de uma empresa que passa noites trabalhando, relegando a família ao descaso; é também o agressor da prostituta chinesa Guo Dongli, o que the confere uma dupla personalidade. Embora se situe em um cenário à parte dentro da obra, chama a atenção o fato de, em determinado momento, um lápis que utilizava em seu escritório aparecer no quarto de Eri Asai.

Apesar dos relógios que marcam as horas no início de cada capítulo, percebese que existe uma oposição entre tempo cronológico e tempo individual/psicológico. Isso se relaciona ao domínio do metafísico, o qual surge na obra em duas instâncias: a noite (centrada em Mari) e também o quarto de Eri. Tal ideia se aplica ao que já foi anteriormente mencionado, a respeito do "outro mundo". De acordo com Strecher (2014:25), o mundo metafísico de Murakami não conhece "passado" ou "presente", sendo apenas um agora sem fim, que se autorrepete. No mundo de Eri, parecem existir transformações espaciais, na medida em que, inicialmente, ela é descrita em seu quarto; posteriormente, o quarto parece ser transposto para dentro da tela de TV (ou para o outro lado da janela) para, em seguida, estabelecer-se uma relação com o escritório de Shirakawa (sugerido pela presença do lápis deste no quarto de Eri e, ainda, pela semelhança do outro lado da tela onde ela está com o escritório de Shirakawa). Durante esse tempo, Eri permanece dormindo, acordando em apenas um momento: dentro da tela, de onde não pode sair.

Em sua análise sobre a obra de Murakami, Strecher (2014:109-110) pondera que, em Após o Anoitecer, o quarto de Eri Asai seria uma representação do útero, onde o ser que ali está deve recriar o seu self para se tornar um ser completo; ela passa, por assim 
dizer, por uma fase de gestação. E, quanto ao "homem sem rosto" que fica sentado, inexpressivo, dentro da tela, ele seria uma espécie de guardião do "outro mundo", nem benevolente, nem malévolo: serviria como um mediador entre as duas irmãs e os mundos distintos que habitam. Eri ainda não consegue sair do estado de letargia que, em termos psicológicos, significa que ainda não consegue atingir um patamar superior de existência, ao contrário do que acontece com Mari. Em especial através de seus diálogos com Takahashi e Koorogui, que a encorajam tanto na questão de sua autoestima como na sua relação com a irmã, ela acaba por adquirir uma confiança que a faz procurar Eri. Ao final, Mari entra em seu quarto e deita-se junto a ela, tentando escutar seu coração. $\mathrm{E}$, nesse momento, as lágrimas fluem:

\footnotetext{
Ela é tomada por uma emoção forte; sente que fez algo - algo que nem mesmo ela sabe o que exatamente é.(...)

Mari dorme na cama, ao lado da irmã. Escutamos um leve ressonar. Até onde podemos observar, é um sono tranquilo. Seu corpo deve estar mais quente e seu rosto mais rosado que da última vez que a vimos. Sua franja cobre parte dos olhos. No canto da boca esboça-se um sorriso. Será que ela está sonhando? Ou será que está se lembrando de algo? Mari passou por um longo período de escuridão e, após conversar com várias pessoas que conhecu durante a noite, finalmente voltou ao seu lugar.(...) (MURAKAMI, 2009:198-203)
}

Através desta conclusão, podemos novamente recorrer aos contos sobre dois irmãos e a questões psicológicas, se pensarmos em Eri e Mari Asai como duas partes de uma única pessoa que, ao final, podem alcançar a integração:

O conto de fadas nos ajuda a entendermo-nos melhor, já que na estória os dois lados de nossa ambivalência são isolados e projetados em personagens diferentes.(...) Quando o conto de fadas indica que estas duas pessoas diferentes são realmente 'irmãos na pele', orienta a criança na direção da percepção pré-consciente de que os dois personagens são, na verdade, duas partes de uma única e mesma pessoa.(...) (BETTELHEIM, 1992:107)

\section{Kafka à Beira-Mar}

Desde o início da narrativa, já nos deparamos com o universalmente conhecido mito de Édipo: Kafka Tamura sofre uma imprecação do pai, com quem mantém um relacionamento conflituoso, de que o matará e dormirá com sua mãe e com sua irmã. Ele então deixa o lar, ao mesmo tempo na tentativa de fugir da profecia e de procurar sua mãe e sua irmã: saindo de Tokyo, vai até Shikoku, à cidade de Takamatsu, onde encontra uma biblioteca. Ele passa a viver ali, sob a proteção de Oshima, o auxiliar do local, e é ali também que conhece a Sra. Saeki, responsável pela bibioteca, com quem manterá um relacionamento incestuoso - visto que, mais tarde, o leitor virá a saber que se trata de sua mãe (ou, pelo menos, as conjecturas expostas na obra levam a essa ideia). Antes disso, ele supostamente mata o pai, fato que ocorre de um modo um tanto abstrato.

Paralelamente à sua história, irá também se desenrolar a saga de Satoru Nakata que, tendo sofrido um acidente inexplicável na infância, que afetou seu lado cognitivo, 
não consegue ler nem escrever. Ele emprega em sua fala apenas a terceira pessoa (ainda quando fala de si mesmo) e tem a faculdade de compreender a linguagem dos gatos e comunicar-se com eles. Com a ajuda de Hoshino, um caminhoneiro, Nakata chega a seu destino, a cidade de Takamatsu.

Murakami mencionou que algumas pessoas dizem que suas personagens são muito passivas; para ele, no entanto, elas têm um tipo diferente de força (In: PHELAN, 2005). À semelhança dos herois dos contos maravilhosos, que simplesmente são lançados à peripécia, sem questionamentos, elas parecem movidas por forças sobrenaturais, que as lançam para o desvendar de um enigma - ou de seus próprios enigmas. Murakami descreve suas histórias como "mistérios sem soluções", expressão que poderia ser lida como uma metáfora para a própria vida. De acordo com Yamada (2009:12), Kakfa deve encontrar o equilíbrio entre sua dependência de uma imprecação que guia sua vida e sua independência em perdoar seu próprio senso do $e u$.

As três personagens centrais de Kafka à Beira-Mar - Kafka, Nakata e Sra. Saeki - estão unidas entre si pelo destino, que as leva a se encontrarem em Takamatsu. Um dos motivos pelos quais poderíamos aventar a possibilidade de Nakata ser um alter ego de Kafka é a morte de Koji Tamura, pai de Kafka que, surgindo aos olhos de Nakata como Johnnie Walker (o ícone do whisky, não possuindo, no entanto, nome nem forma definidos), é instigado por este a assassiná-lo. Nakata comete o crime "físico"; mas, no corpo, não lhe resta nenhuma marca da execução. Quem aparece sujo de sangue é Kafka, quando acorda em um santuário xintoísta em Takamatsu; onde, aliás, encontra-se a "pedra da entrada", aberta pela Sra. Saeki e seu namorado, na época em que eram jovens, para que o mundo idílico em que viviam não fosse destruído. Cabe então a Nakata encontrar a pedra e fechar a entrada, para que as coisas voltassem à forma original. Ou seja, existe também uma relação estreita entre Nakata e a Sra. Saeki, mesmo porque ambos reconhecem, quando finalmente se encontram, que só possuíam metade de sua sombra - Nakata, vivendo apenas o presente (devido à memória que perdera), e a Sra. Saeki, as lembranças do passado.

Para solucionarem os mistérios que atormentavam suas vidas, tanto Nakata quanto Kafka contam com o auxílio de outras personagens, de uma forma que se assemelha aos contos maravilhosos. Podemos, assim, recorrer aos actantes a respeito dos quais Propp discorreu em seu estudo acerca das funções dos contos maravilhosos. Alguns deles são diferentes para cada um dos protagonistas - que podem ser qualificados na esfera do heroi. No caso de Kafka, o doador seria Oshima, visto que provê ao adolescente abrigo, companhia, conselho e, quando necessário, uma rota de fuga (STRECHER, 2014:89). Talvez pudéssemos atribuir também a ele o papel de auxiliar (ajudante), mesmo porque uma mesma personagem pode assumir funções diferentes dentro de uma narrativa.

Quanto a Nakata, poderíamos dizer que o auxiliar seria Hoshino, o caminhoneiro que o acompanha em sua jornada à ilha de Shikoku. E o doador seria o Coronel 
Sanders, pois é ele quem guia Hoshino até a pedra da entrada, que se localizava no santuário xintoísta onde Kafka surge desacordado, após Nakata (ou ele próprio?) matar seu pai.

A Sra. Saeki figura, tanto para Kafka quanto para Nakata, como a personagem procurada (que, na maioria dos contos de fadas, surge como a princesa). Percebemos isso no capítulo 42, quando a Sra. Saeki diz a Nakata, quando se encontram na biblioteca, que ela estava à sua espera, e o velho concorda. E, na esfera de Kafka, isso se dá no capítulo 47, quando acontece o diálogo decisivo entre ele e a Sra. Saeki, em que parece se desvendar a relação entre ambos. No caso, talvez seja preferível deixar a ideia nas entrelinhas, uma vez que nem todos os leitores concordam que o mistério da maternidade de Kafka seja esclarecido por Murakami na obra.

Quanto ao antagonista, é difícil detectar sua presença na história. No entanto, é possível imaginar que Johnnie Walker o seja, em especial pelo embate que se trava entre ele e o Menino Chamado Corvo, em uma parte que, embora pareça um capítulo, surge sem numeração, localizado entre os capítulos 46 e 47. Seria como uma luta entre pai e filho (se considerarmos o Menino Chamado Corvo como outro alter ego de Kafka Tamura); no entanto, não há nem vencido, nem vencedor. Poderíamos dizer que se trata de uma luta simbólica.

A grande mudança na vida de Kafka Tamura acontece quando ele adentra a floresta onde ficava a cabana de Oshima, na província de Kochi. Isso acontecera uma primeira vez quando, advertido por Oshima, não adentrou a floresta temendo suas armadilhas. Mas, da segunda vez, ainda que ciente do perigo, decide entrar e enfrentar seus "fantasmas". Quando Oshima fala dos perigos da floresta, ele faz uma analogia com um labirinto:

- (...) O que existe externamente é uma projeção do que existe em você, e o que existe em você é a projeção do que existe externamente. Assim sendo, muitas vezes, ao pôr um pé no labirinto externo, você está pondo um pé no labirinto existente em você. E isso, na maioria das vezes, é muito perigoso.

- Como João e Maria entrando na floresta.

- Isso mesmo. Como João e Maria. A floresta prepara uma armadilha. Por mais que você se cuide e use de artifícios, pássaros de olhar aguçado encontram os farelos sinalizadores e os comem." (MURAKAMI, 2008:433)

Vemos aqui uma referência ao conto João e Maria, dos Irmãos Grimm. Já foi colocado anteriormente que, para Propp, a entrada do heroi em uma floresta ou num reino divisado por um rio evoca uma conexão entre o mundo dos vivos e o dos mortos, assim como a existência de dois mundos em diversas das obras de Murakami. Dessa forma, a entrada de Kafka Tamura na floresta seria interpretada como um rito de passagem de um adolescente de quinze anos em busca de sua identidade; e, ainda, podemos considerar a floresta como representação do inconsciente, enquanto domínio metafísico. Quando Kafka adentra a floresta guiado pelos dois soldados desertores, ele é conduzido a uma pequena vila, onde encontra a Sra. Saeki jovem, que vem lhe preparar todas as refeições. 
Posteriormente, é a Sra. Saeki adulta quem lhe aparece para falar sobre sua morte e pedindo-lhe para que voltasse para o seu mundo. Aqui, é importante considerar que o inconsciente é atemporal: não existe passado ou presente no mundo metafísico de Murakami. Assim como no universo dos contos maravilhosos e dos mukashi banashi, quando o tempo é apenas vagamente marcado: Mukashi, mukashi, aru tokoro ni... (“Antigamente, há muito tempo...”), numa demonstração de vaga temporalidade.

\section{Considerações finais}

Uma questão que sempre - ou quase sempre - intriga os leitores de Murakami refere-se ao final de suas obras. O autor diz que não há respostas em seu mundo ficcional, apenas sonhos. "Muitas pessoas me dizem que elas não sabem o que sentir quando terminam algum de meus livros porque a história é sombria, ou complicada, ou estranha', diz Murakami. 'Mas enquanto elas leem, estão dentro do meu mundo e estão felizes. Isso é bom." ${ }^{6}$

De acordo com o que foi brevemente exposto, podemos dizer que, pensando-se na relação entre mito/conto maravilhoso/mukashi banashi e as duas obras de Murakami, teríamos em Kafka à Beira-Mar uma resolução parcial dos conflitos, podendo considerálo um meio-termo entre as narrativas ocidentais - as quais, em sua grande maioria, têm um "final feliz" e todos os mistérios são solucionados - e as japonesas. Imaginamos tal fato pela integração que parece ocorrer na obra, quando percebemos Kafka, Nakata e a Sra. Saeki reunidos no quadro que o namorado desta lhe dera de presente. Quando se encontra com Nakata, ela lhe diz:

- Tenho a impressão de que o conheço há muito, muito tempo - disse a Sra. Saeki. - Você não estaria nesse quadro? Essa pessoa que está com a barra da calça branca arregaçada e pés na água no fundo da pintura não seria você? (MURAKAMI, 2008:483)

E, depois, para Kafka:

- (...) eu disse que legava o quadro a você, Kafka. Sobretudo porque aquele quadro era originalmente seu.

- Meu?

Ela assente.

- Pois você estava lá. E eu, a seu lado, o observava. Na praia, muitos, muitos anos atrás... A brisa soprava do mar, nuvens brancas flutuavam no céu e era sempre verão. (MURAKAMI, 2008:540)

Este trecho sugere que Kafka e o namorado da Sra. Saeki seriam a mesma pessoa, fato que, no universo do inconsciente - atemporal - seria possível. Por outro lado, a

6. "Many people tell me that they don "t know what to feel when they finish one of my books because the story was dark, or complicated, or strange," Murakami says. "But while they were reading it, they were inside my world and they were happy. That's good.”. (PHELAN, 2005) 
obra apresenta um final "em aberto", na medida em que, conversando com o Menino Chamado Corvo, Kafka sente que ainda não sabe o que é viver. Adormece e, ao acordar, "é parte de um novo mundo".

No caso de Após o Anoitecer, Mari Asai, que saiu de casa, consegue encontrar a solução para seu conflito. Eri, por outro lado, fica em casa dormindo, ainda à espera da maturidade - como que numa "fase de gestação". Podemos considerar que o fato de Mari deitar-se junto de sua irmã simbolizaria uma futura e suposta integração entre ambas, de que haveria uma possiblidade de Eri sair de seu sono profundo.

Nas duas obras, o confronto das personagens com a morte é evidente: a condição de letargia em que Eri se encontrava aproxima-a da morte. No entanto, como sugerem os contos de fadas, essa condição pode ser revertida, o que em Após o Anoitecer podemos vislumbrar com a aproximação, ao final, que acontece entre as duas irmãs. No caso de Kafka à Beira-Mar, ao adentrar a floresta, Kafka pode optar por sair ou não dela; caso não saísse, estaria fadado à morte. Através de sua escolha, o adolescente retoma sua jornada rumo a um patamar superior de existência. E mais um ciclo da roda da vida tem início.

\section{Referências bibliográficas}

BETTElHeiM, Bruno. A Psicanálise dos Contos de Fadas. Rio de Janeiro: Paz e Terra, 1992.

MEletínsKi, E.M. A Poética do Mito. Trad. Paulo Bezerra. Rio de Janeiro: Forense Universitária, 1987.

MURAKAMI, Haruki. Após o Anoitecer. Trad. Lica Hashimoto. Rio de Janeiro: Objetiva, 2009. Kafka à Beira-Mar. Trad. Leiko Gotoda. Rio de Janeiro: Objetiva, 2008.

PHELAN, Stephen. Dark master of a dream world. The Age, Melbourne, February, 2005. Retrieved 2008-04-24. Disponível em http://www.theage.com.au/news/Books/Darkmaster-of-a-dream-world/2005/02/03/1107409993322.html .

PROPP, Vladimir. As Raízes Históricas do Conto de Magia. Trad. José Martín Arancibia. Madrid: Fundamentos, 1974 (versão em espanhol).

STRECHER, Matthew Carl. Beyond "Pure" Literature: Mimesis, Formula, and the Postmodern in the Fiction of Murakami Haruki. The Journal of Asian Studies, v.57, n.2, p.354-378, maio, 1998.

The Forbidden Worlds of Haruki Murakami. Minneapolis: University of Minnesota Press, 2014.

YAMADA, Marc. Exposing the Private Origins of Public Stories: Narrative Perspective and the Appropriation of Selfhood in Murakami Haruki's Post-AUM Metafiction. Japanese Language and Literature, v.43, n.1, p.1-26, abril, 2009.

Dissertações e teses

NAMEKATA, Márcia Hitomi. Os Mukashi Banashi (Narrativas Antigas) da Literatura 
Japonesa: Análise de sua Evolução no Universo Japonês. São Paulo, 1999. Dissertação (Mestrado em Língua, Literatura e Cultura Japonesa - Faculdade de Filosofia, Letras e Ciências Humanas. Universidade de São Paulo).

. Os Mukashi Banashi da Literatura Japonesa: Uma Análise do Feminino e do Casamento Entre Seres Diferentes no Contexto dos Contos do Japão Antigo. São Paulo, 2011. Tese (Doutorado em Teoria Literária e Literatura Comparada - Faculdade de Filosofia, Letras e Ciências Humanas. Universidade de São Paulo). 